\title{
INDICE DEI MANOSCRITTI CITATI
}

Baltimore - Walters Art Gallery 483 (372): 23, 26

Bern - Burgerbibliothek

A 92: 71

330: 22, 24-26, 28, 30, 35, 36

$338: 22,24-26,28,30,35,36$

417: $56,57,58$

432: 23,24

Bologna - Biblioteca Universitaria 797 (483): 22, 24, 25

Cambridge - Corpus Christi College 221: 22, 24-26, 28, 30, 32, 35

Cambridge - Sidney Sussex College $75: 23,24-26$

Göttingen - Niedersächsische Staats- und

Universitätsbibliothek Nachlass W. Meyer 43: 23, 28

Karlsruhe - Badische Landesbibliothek Aug. CXII: 56, 75

Leiden - Bibliotheek der Rijksuniversiteit BPL 135: 51, 52, 55, 58, 59, 61, 65,78

B.P.L. 156: 24

B.P.L. 191 E: 23-26

Voss. Q.33: 71

London - British Library, Harley 3969: 23, 26, 28, 36

Manchester - John Rylands Library lat. 116: 70

Milano - Biblioteca Ambrosiana

F 58 sup.: 23,28

Q 37 sup.: 23, 28

Montpellier-Bibliothèque. Interuniversitaire,

Section de Médecine

H 160: 22, 24

H 306: 22, 24-26, 28, 32, 35, 36

München - Bayerische Staatsbibliothek

Clm 601: 22, 24

Clm 6355:155: 55, 60, 78

Napoli - Biblioteca Nazionale,

IV A 34:22,24-26, 28, 30, 32, 35, 36, 38

IV E 52:23
S. Martino agg. 86: 23, 26

Oxford - Bodleian Library,

Bodley 186: 23-26

Paris - Bibliothèque Nationale

lat. 1750: $56-58$

lat. $7533: 51,55,58-60$

lat. 7491: 22, 24-26

lat. 11313: 24, 36

lat. $13025: 23,56-58$

nouv. acq. lat. 907: 23

nouv. acq. lat. 909: 23

San Daniele del Friuli - Biblioteca Guarneriana 84: 24

Sankt Gallen - Stiftsbibliothek

249: 23-26,28, 30, 32, 36

908: 69

913: 69

Savignano sul Rubicone - Biblioteca della

Rubiconia Accademia dei Filopatridi 9: $23,26,28$

Siena - Biblioteca Comunale degl'Intronati G IX 38:23, 26, 28

Città del Vaticano - Biblioteca Apostolica

Vaticana

Barb. lat. 47: 23

Reg. lat. 1818: 23, 26

Reg. Lat. 2078: 22, 24-26, 28, 30, 32, 36

Urb. lat. 308: 24

Vat. lat. 1491: 23, 26

Vat. lat. 1492: 23, 26

Wien - Österreichische Nationalbibliothek lat. 2245: 69 